\title{
Effect of $\gamma$-Oryzanol on Cytochrome P450 Activities in Human Liver Microsomes
}

\author{
Ken Umehara, * Yoshihiko Shimokawa, and Gohachiro Miyamoto \\ Tokushima Research Institute, Otsuka Pharmaceutical Co., Ltd.: 463-10 Kagasuno, Kawauchi-cho, Tokushima 771-0192, \\ Japan. Received November 20, 2003; accepted March 17, 2004
}

The effects of $\gamma$-oryzanol, a drug mainly used for the treatment of hyperlipidaemia, on several cytochrome P450 (CYP) specific reactions in human liver microsomes were investigated to predict drug interactions with $\gamma$ oryzanol in vivo from in vitro data. The following eight CYP catalytic reactions were used in this study: CYP1A1/2-mediated 7-ethoxyresorufin $O$-deethylation, CYP2A6-mediated coumarin 7-hydroxylation, CYP2B6mediated 7-benzyloxyresorufin $O$-debenzylation, $\mathrm{CYP2C8} / 9$-mediated tolbutamide methylhydroxylation, CYP2C19-mediated $S$-mephenytoin 4'-hydroxylation, CYP2D6-mediated bufuralol 1'-hydroxylation, CYP2E1mediated chlorzoxazone 6-hydroxylation, and CYP3A4-mediated testosterone $6 \beta$-hydroxylation. $\gamma$-Oryzanol had little inhibitory effects on CYP activities, indicating that this compound would not be expected to cause clinically significant interactions with other CYP-metabolized drugs at expected therapeutic concentrations.

Key words $\gamma$-oryzanol; in vitro drug-drug interaction; human liver microsome

\begin{abstract}
$\gamma$-Oryzanol is a substance extracted from rice bran oil, and it has been widely used clinically due to its effectiveness in treating autonomic imbalance and menopausal disorders. In addition, it has been reported that $\gamma$-oryzanol also has a cholesterol-lowering effect. ${ }^{1-3)} \gamma$-Oryzanol is mainly metabolized to ferulic acid in animals and humans (Fig. 1). ${ }^{4-7)}$ Following a single oral administration of $\gamma$-oryzanol at $300 \mathrm{mg}$ to humans, the peak plasma concentrations of $\gamma$-oryzanol and ferulic acid were $37.6 \mathrm{ng} / \mathrm{ml}$ and $36.6 \mathrm{ng} / \mathrm{ml}$, respectively. ${ }^{4)}$ Ferulic acid was excreted in urine at $2.4-2.8 \%$ of the dose/d but $\gamma$-oryzanol was not detected.
\end{abstract}

Most oxidative metabolism of drugs is catalyzed by cytochrome P450 (CYP) enzymes, which comprise a large family of hemoproteins. ${ }^{8,9)}$ More than 15 isozymes have been identified in human liver, and several forms play important roles in the metabolism of drugs. ${ }^{10)}$ It is important to identify the enzymes responsible for the metabolism of drugs and to investigate further whether a drug has an inhibitory effect on the catalytic activity of each CYP enzyme to consider possible drug interactions. A previous in vitro study showed that $\gamma$-oryzanol was hydrolyzed to ferulic acid in rat liver, intestine, pancreas and kidney preparations, with possible involvement of carboxylesterase. ${ }^{11)}$ However, it is unclear whether $\gamma$-oryzanol has an inhibitory effect on CYP catalytic activities. In this study, we examined the characteristic properties of $\gamma$-oryzanol on the catalytic activities of CYP1A1/2, CYP2A6, CYP2B6, CYP2C8/9, CYP2C19, CYP2D6, CYP2E1, and CYP3A4 using specific reaction probes for the enzymes.

\section{MATERIALS AND METHODS}

Chemicals $\gamma$-Oryzanol was supplied by Otsuka Pharma-

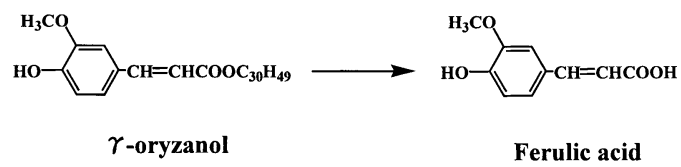

Fig. 1. Proposed Biotransformation Pathway for $\gamma$-Oryzanol in Humans ceutical Co., Ltd. (Tokyo, Japan). Coumarin, tolbutamide, chlorzoxazone, glucose-6-phosphate disodium salt:hydrate, and $\beta$-NADP sodium salt were purchased from Sigma Chemical Co. (St. Louis, MO, U.S.A.). Other chemicals were obtained from the following sources: 7-ethoxyresorufin, 4-hydroxytolbutamide, $S$-(+)-mephenytoin, $\quad( \pm)-4$ '-hydroxymephenytoin, $1^{\prime}$-hydoxybufuralol maleate salt, ( \pm )-bufuralol hydrochloride salt, 6-hydroxychlorzoxazone, and $6 \beta$-hydroxytestosterone from Salford Ultrafine Chemical \& Research Ltd. (Guildhall Close, Manchester, U.K.); 7-benzyloxyresorufin from Molecular Probes (Eugene, OR, U.S.A.); 7-hydroxycoumarin from Tokyo Chemical Industry Co., Ltd. (Tokyo, Japan); resorufin, testosterone, and magnesium chloride hexahydrate from Wako Pure Chemical Industries, Ltd. (Osaka, Japan); and glucose-6-phosphate dehydrogenase (approximately $350 \mathrm{U} / \mathrm{mg}, 1 \mathrm{mg} / \mathrm{ml}$ ) from Boehringer Mannheim GmbH (Mannheim, Germany). All other reagents and solvents were of high analytical grade.

Liver Microsome Preparation Pooled human liver microsomes from 10 donors were prepared at the Biomedical Research Institute, Human and Animal Bridge Discussion Group (HAB, Chiba, Japan). Human liver samples were legally procured from the National Disease Research Interchange (NDRI, PA, U.S.A.) through the international partnership between the NDRI and HAB. The study was conducted in accordance with the Declaration of Helsinki. Human livers were homogenized with $0.25 \mathrm{M}$ sucrose containing $3 \mathrm{~mm}$ Tris and $0.1 \mathrm{~mm}$ EDTA ( $\mathrm{pH} 7.4$ ), and microsomes were isolated by differential centrifugation using the common method. ${ }^{12)}$ Washed microsomes were resuspended in $100 \mathrm{~mm}$ Tris- $\mathrm{HCl}$ buffer ( $\mathrm{pH} 7.4$ ) containing $1 \mathrm{~mm}$ EDTA and $20 \%$ glycerol at protein concentrations of $20 \mathrm{mg} / \mathrm{ml}$.

Determination of Human CYP Activities 7-Ethoxyresorufin $O$-deethylase activity by CYP1A1/2, coumarin 7-hydroxylase activity by CYP2A6, 7-benzyloxyresorufin $O$ debenzylase activity by CYP2B6, tolbutamide methylhydroxylase activity by CYP2C8/9, $S$-mephenytoin $4^{\prime}$-hydroxylase activity by CYP2C19, bufuralol 1 '-hydroxylase activity by CYP2D6, chlorzoxazone 6-hydroxylase activity by CYP2E1, and testosterone $6 \beta$-hydroxylase activity by CYP3A4 were 
determined as previously described. ${ }^{13)}$

Standard incubation mixtures of $0.5 \mathrm{ml}$ contained microsomal protein $(0.1-0.5 \mathrm{mg}), 0.1 \mathrm{M}$ potassium phosphate buffer (pH 7.4), 0.1 mM EDTA, NADPH-generating system $(2.5 \mathrm{~mm}$ $\beta$-NADP, $25 \mathrm{~mm}$ glucose-6-phosphate, 2 units of glucose-6phosphate dehydrogenase, and $10 \mathrm{~mm}$ magnesium chloride), and substrates with or without $\gamma$-oryzanol. $\gamma$-Oryzanol was dissolved in dimethyl sulfoxide and added to incubations at a volume of $5 \mu \mathrm{l}$. The precipitate of test compound was not visually observed in the reaction system. Substrates were dissolved in the following solvents: 7-ethoxyresorufin and 7benzyloxyresorufin in dimethyl sulfoxide; coumarin and bufuralol in ethanol; tolbutamide, $S$-mephenytoin, and testosterone in methanol; and chlorzoxazone in $1 \%(\mathrm{w} / \mathrm{v})$ aqueous sodium carbonate. They were added to incubations at a volume of $5 \mu \mathrm{l}$. Product formation was determined using HPLC and a fluorescence spectrophotometer. Enzyme incubations and metabolite analysis were carried out in duplicate.

Assay methods were validated in this study. Calibration curves for resorufin, 7-hydroxycoumarin, 4-hydroxytolbutamide, 4-hydroxymephenytoin, 1'-hydroxybufuralol, 6-hydrochlorzoxazone, and $6 \beta$-hydroxytestosterone were established with respective calibration ranges of $0.2-200 \mathrm{~nm}(\gamma=$ $0.9996), 0.025-5 \mu \mathrm{M}(\gamma=1.0000), 0.05-10 \mu \mathrm{M}(\gamma=0.9998)$, $0.025-5 \mu \mathrm{M}(\gamma=0.9996), 0.025-5 \mu \mathrm{M}(\gamma=0.9995), 0.25-$ $100 \mu \mathrm{M}(\gamma=0.9994)$, and $0.03-30 \mu \mathrm{M}(\gamma=0.9999)$.

The substrate concentrations used to estimate the kinetic parameters for each assay were 7-ethoxyresorufin $0.01-$ $10 \mu \mathrm{M}$, coumarin $0.1-100 \mu \mathrm{M}, 7$-benzyloxyresorufin 0.03 $10 \mu \mathrm{M}$, tolbutamide $25-1000 \mu \mathrm{M}, S$-mephenytoin 5-500 $\mu \mathrm{M}$, bufuralol 5-200 $\mu \mathrm{M}$, chlorzoxazone $10-400 \mu \mathrm{M}$, and testosterone $10-250 \mu \mathrm{M}$. For the determination of residual activity in the presence of $\gamma$-oryzanol $(1-30 \mu \mathrm{g} / \mathrm{ml})$, the concentrations of substrates were 7-ethoxyresorufin $0.5 \mu \mathrm{M}$, coumarin $2 \mu \mathrm{M}$, 7-benzyloxyresorufin $1 \mu \mathrm{M}$, tolbutamide $100 \mu \mathrm{M}, S$-mephenytoin $100 \mu \mathrm{M}$, bufuralol $20 \mu \mathrm{M}$, chlorzoxazone $100 \mu \mathrm{M}$, and testosterone $100 \mu \mathrm{M}$. Selective CYP inhibitors were used in this study to validate that the assays were working properly. 7,8-Benzoflavone, ${ }^{14}$ furafylline, ${ }^{15}$ ) orphenadrine, ${ }^{16)}$ quercetin, ${ }^{17)}$ sulfaphenazole, ${ }^{18)}$ tranylcypromine, ${ }^{19)}$ quinidine ${ }^{20)}$ diethyldithiocarbamate, ${ }^{21)}$ and ketoconazole, ${ }^{22)}$ which are inhibitors of CYP1A1, 1A2, 2B6, 2C8, 2C9, 2C19, 2D6, 2E1, and 3A4, respectively, inhibited the respective enzyme activities (data not shown). Diethyldithiocarbamate is also known to be a specific inhibitor of CYP2A6, ${ }^{14)}$ and the present study confirmed the potent in- hibitory capability of this compound on CYP2A6-mediated metabolism (data not shown).

Data Analysis Apparent $K_{\mathrm{m}}$ and $V_{\max }$ values for the formation of metabolites were calculated using nonlinear regression analysis on the computer program WinNonlin Standard (Version 2.1, Scientific Consulting, Inc., Apex, NC, U.S.A.).

\section{RESULTS AND DISCUSSION}

Multiple-drug therapy is a common therapeutic practice, particularly for patients with various diseases. Whenever two or more drugs are administered concurrently, there is the possibility of drug interactions. Many drug interactions are clinically caused by inhibition of drug-metabolizing enzymes, CYPs, leading to decreased metabolic clearance and increased exposure to the inhibited drug. The inhibition of CYP enzymes should thus be examined to assess the potential for drug interactions.

The current study examines the in vitro ability of $\gamma$ oryzanol to inhibit the metabolism of substrates for CYP1A1/2, CYP2A6, CYP2B6, CYP2C8/9, CYP2C19, CYP2D6, CYP2E1, and CYP3A4. $\gamma$-Oryzanol had almost no inhibitory effects on CYP-mediated pathways (Table 1).

After an oral dose of $600 \mathrm{mg}$ in healthy volunteers, the peak plasma concentration range of $\gamma$-oryzanol was 21.0 to $106.8 \mathrm{ng} / \mathrm{ml}^{4}{ }^{4}$ Moreover, the steady-state peak plasma concentration of $\gamma$-oryzanol was $111.7 \mathrm{ng} / \mathrm{ml}$ after repetitive oral administration of $\gamma$-oryzanol at $100 \mathrm{mg}$ three times a day for $10 \mathrm{~d}^{5}{ }^{5}$ To extrapolate in vitro inhibition data to in vivo situations, free concentrations of drug and inhibitor at the site of metabolism are important. ${ }^{23,24)}$ However, it is difficult to evaluate the free concentration of $\gamma$-oryzanol at an enzyme site due to the lack of information about the plasma protein binding of $\gamma$-oryzanol. The lower plasma level of $\gamma$-oryzanol compared with the highest tested concentration $(30 \mu \mathrm{g} / \mathrm{ml})$ suggested that $\gamma$-oryzanol would cause little or no inhibitory effect on the metabolism of drugs metabolized by CYPs even if intracellular binding or accumulation of $\gamma$-oryzanol in hepatocytes occurs. In addition, there are no clinical reports indicating that $\gamma$-oryzanol causes drug-drug interactions with other CYP-metabolized drugs.

In conclusion, the results of the in vitro experiments performed with human liver microsomes indicate that $\gamma$ oryzanol has little inhibitory effect on CYP-mediated catalytic activities and that this compound, at anticipated thera-

Table 1. Effect of $\gamma$-Oryzanol on Cytochrome P450-Catalyzed Oxidase Activities in Human Liver Microsomes

\begin{tabular}{|c|c|c|c|c|c|c|c|}
\hline \multirow{2}{*}{ CYP } & \multirow{2}{*}{ Reaction } & \multirow{2}{*}{$K_{\mathrm{m}}(\mu \mathrm{M})$} & \multirow{2}{*}{$V_{\max }(\mathrm{pmol} / \mathrm{min} / \mathrm{mg}$ protein $)$} & \multicolumn{4}{|c|}{$\%$ Control activity } \\
\hline & & & & $1 \mu \mathrm{g} / \mathrm{ml}$ & $3 \mu \mathrm{g} / \mathrm{ml}$ & $10 \mu \mathrm{g} / \mathrm{ml}$ & $30 \mu \mathrm{g} / \mathrm{ml}$ \\
\hline CYP1A $1 / 2$ & 7-Ethoxyresorufin $O$-deethylation & 0.519 & 15.0 & 85 & 86 & 86 & 84 \\
\hline CYP2A6 & Coumarin 7-hydroxylation & 1.73 & 163 & 86 & 86 & 85 & 81 \\
\hline CYP2B6 & 7-Benzyloxyresorufin $O$-debenzylation & 1.59 & 4.83 & 93 & 98 & 85 & 71 \\
\hline CYP2C8/9 & Tolbutamide methylhydroxylation & 442 & 84.9 & 96 & 100 & 98 & 98 \\
\hline CYP2C19 & $S$-Mephenytoin $4^{\prime}$-hydroxylation & 86.0 & 8.54 & 100 & 100 & 100 & 96 \\
\hline CYP2D6 & Bufuralol 1'-hydroxylation & 21.7 & 61.0 & 109 & 105 & 108 & 108 \\
\hline CYP2E1 & Chlorzoxazone 6-hydroxylation & 115 & 2600 & 96 & 102 & 104 & 96 \\
\hline CYP3A4 & Testosterone $6 \beta$-hydroxylation & 136 & 5540 & 99 & 98 & 94 & 91 \\
\hline
\end{tabular}

The control activities were $7.25,74.8,1.44,8.52,2.39,10.9,109$, and 1490 pmol/min/mg for CYP1A1/2-, CYP2A6-, CYP2B6-, CYP2C8/9-, CYP2C19-, CYP2D6-, CYP2E1-, and CYP3A4-catalyzed reactions, respectively. The values of the percent of control activity are the average of duplicate determinations (control=100\%). 
peutic concentrations, would not be expected to cause clinically significant interactions with other CYP-metabolized drugs.

\section{REFERENCES}

1) Kuzuya F., Yoshimine N., Kato S., Fujita K., Ushigome H., Geriatric Medicine, 18, 519-524 (1980).

2) Shinomiya M., Morisaki N., Fujiyama Y., Shirai K., Saito Y., Kumagai A., Matsuoka N., Murano S., Mitani K., Morita S., J. Jpn. Atherosclerosis Soc., 10, 1069-1075 (1983).

3) Mitani K., Kido Y., Shimizu S., Morita S., J. Jpn. Atherosclerosis Soc., 11, 411-416 (1983).

4) Odomi M., Ishigami M., Shimizu T., Otsuka Pharmaceut. In-House Rep., (1983).

5) Odomi M., Matsuura K., Shimizu T., Otsuka Pharmaceut. In-House Rep., (1985).

6) Fujiwara S., Noumi K., Sugimoto I., Awata N., Chem. Pharm. Bull., 30, 973-979 (1982).

7) Fujiwara S., Sakurai S., Sugimoto I., Awata N., Chem. Pharm. Bull., 31, 645-652 (1983).

8) Guengerich F. P., Life Sci., 50, 1471-1478 (1992).

9) Gonzalez F. J., Pharmacol. Rev., 40, 243-288 (1989).

10) Kerremans A. L. M., Neth. J. Med., 48, 237-243 (1996).

11) Kudo S., Akiyama H., Otsuka Pharmaceut. In-House Rep., (1982).

12) Emoto C., Yamazaki H., Iketaki H., Yamasaki S., Satoh T., Shimizu R., Suzuki S., Shimada N., Nakajima M., Yokoi T., Xenobiotica, 31,
$265-275(2001)$

13) Ikeda T., Nishimura K., Taniguchi T., Yoshimura T., Hata T., Kashiyama E., Kudo S., Miyamoto G., Kobayashi H., Kobayashi S., Okazaki O., Hakusui H., Aoyama E., Yoshimura Y., Yamada Y., Yoshikawa M., Otsuka M., Niwa T., Kagayama A., Suzuki S., Satoh T., Xenobio. Metabol. Dispos., 16, 115-126 (2001).

14) Correia M. A., "Cytochrome P450: Structure, Mechanism, and Biochemistry," ed. by Ortiz de Montellano P. R., Plenum Press, New York, 1995, pp. 607-630.

15) Sesardic D., Boobis A. R., Murray B. P., Murray S., Segura J., Torre R. D., Davies D. S., Br. J. Clin. Pharmacol., 29, 651-663 (1990).

16) Stevens J. C., White R. B., Shih H. H., Martinet M., J. Pharmacol. Exp. Ther., 282, 1389-1395 (1997).

17) Rahman A., Korzekwa K. R., Grogan J., Gonzalez F. J., Harris J. W., Cancer Res., 54, 5543-5546 (1994).

18) Rettie R. E., Korzekwa K. R., Kunze K. L., Lawrence R. F., Eddy A. C., Aoyama T., Gelboin H. V., Gonzalez F. J., Trager W. F., Chem. Res. Toxicol., 5, 54-59 (1992).

19) Inaba T., Jurima M., Mahon W. A., Kalow W., Drug Metab. Dispos., 13, 443- 448 (1985).

20) Broly F., Libersa C., Lhermitte M., Bechtel P., Dupuis B., Br. J. Clin. Pharmacol., 28, 29-36 (1989).

21) Guengerich F. P., Kim D. H., Iwasaki M., Chem. Res. Toxicol., 4, 168-179 (1991).

22) Baldwin S. J., Bloomer J. C., Smith G. J., Ayrton A. D., Clarke S. E., Chenery R. J., Xenobiotica, 25, 261-270 (1995).

23) Bertz R. J., Clin. Pharmacokinet., 32, 210-258 (1997).

24) Lin J. H., Lu A. Y. H., Clin. Pharmacokinet., 35, 210-258 (1998). 